\title{
THE INFLUENCE OF PROFESSIONAL STRESS IN PERMANENT WORKING CAPABILITY OF WORKERS WITH ARTERIAL HYPERTENSION AND ITS COMPLICATIONS
}

\author{
Jovica Jovanović $^{1,2}$, Ivana Šarac ${ }^{3}$, Jovana Jovanović ${ }^{1}$, Dušan Sokolović ${ }^{1}$, Stefan Jovanović ${ }^{1}$ \\ ${ }^{1}$ University of Niš, Faculty of Medicine, Niš, Serbia \\ ${ }^{2}$ Institute of Occupational Health Niš, Niš, Serbia \\ ${ }^{3}$ Institute for Medical Research, University of Belgrade, Center of Research Excellence in Nutrition and Metabolism, \\ Belgrade, Serbia
}

\begin{abstract}
Arterial hypertension is widespread in the population of workers. Stress at work has a significant impact on the emergence of many psychosomatic diseases including arterial hypertension. The aim of this research is to show the influence of professional stress on the occurrence of arterial hypertension, its complications and the permanent working ability of exposed workers in construction. The survey covered 1900 construction workers. The standardized questionnaire has assessed the level of stress and professional stressors in their workplaces. The survey group consisted of 1350 workers whose level of total professional stress index (OSI) was over 60, and a control group of 550 workers with an OSI level below 60. The prevalence of arterial hypertension and its complications is statistically significantly more frequent in the examined than in the control group. In the investigated group, a statistically significant number of workers were registered, who, due to their complete loss of working ability, were sent to the disability commission. With an increase in OSI values above 71, the number of workers with complete loss of working capacity is significantly increased in relation to the number of workers who are capable of working. Professional stress is a significant factor that affects the occurrence of arterial hypertension, its complications on vital organs, which lead to a complete permanent loss of working ability of exposed workers in construction.
\end{abstract}

Key words: professional stress, arterial hypertension, complications of arterial hypertension, work ability, construction.

\section{Introduction}

Stress at work is expanding and it has a major impact on the emergence of many psychosomatic diseases including arterial hypertension [1-3]. Arterial hypertension is widespread in the population of workers [4-6] and represents a significant medical and economic problem $[7,8]$. Our previous research has shown a significant impact of stress on the work on temporary inability to work with workers with arterial hypertension [9]. Particularly important is the question of the impact of stress on the long-term ability of exposed workers.

\begin{abstract}
Aim
The purpose of this research is to demonstrate the impact of professional stress on the occurrence of arterial hypertension, its complications and the permanent working ability of the exposed workers in construction industry.
\end{abstract}

Correspondence to: Jovica Jovanović, M.D., Ph.D.

Faculty of Medicine, 81 Zoran Đinđić Blvd., 18000 Niš, Serbia

Phone: +381642614485

E-mail: joca@medfak.ni.ac.rs

Received May $13^{\text {th }}, 2018$, Accepted June $13^{\text {th }}, 2018$

\section{Methodology}

The survey covered 1900 construction workers. In all respondents, the use of a standardized questionnaire with the approval of the author was performed by an analysis of stress factors at the workplace and the calculation of the overall professional stress index (OSI). This method is based on the application of a workplace questionnaire containing 9 areas whose responses are graded with a scale of 0 to 2 , where 0 means "not present", while 2 means "very present". The application of the computer program determined the total Occupational Stress Index (OSI score), which represents the total stress on stressful working conditions, as well as the burden on certain groups of professional stressors. A standardized questionnaire was written by Dr. Karen Belkić [10], who divided the stresses in the workplace into 7 groups (high job demands, rigor, conflict, subcontract, exposure to hazards, time limit, and exposure to noxiousness). The questionnaire encompasses 79 factors which are divided into a two-dimensional matrix, where in the vertical axis is the level of transmission of the information represented in a human (information reception, decision-making, operation and general level) and on the horizontal axis are the aspects of stress (sub-load, high requirements, time less, avoidance of danger and conflicts). Each element has a set of co- 
ordinates so that it is possible to make a total sum of all aspects where the sum of the sums of all elements makes a total OSI score that quantifies the total burden of professional stresses. Each element counts from 0 to 2 points $(0-$ no presence, $2-$ strong presence), so the biggest score is for the highest exposure in the workplace. The sum of all elements of each aspect of stress at a certain level of information transfer is calculated, as well as the total sum of a certain aspect of stress at all levels of information transfer. Aspect underload implies acceptance of similar signal, receiving rare signals, working alone without the need to communicate with other people, making decisions automatically based on the information received, the execution of the same, simple tasks, fixed salary regardless of our work, the inadequacy of wages for the environmental needs of workers and their family, failure to progress and lack of recognition for work, monotonous work. The high demand aspect includes the existence of several sources of information at the same time, diverse information, primary visual observation, high flow of incoming information, three sensory stimulus at the same time, the need for communication at work, complex and quick decisions affecting associates, pay for performance, lack of pause, shift and night work, and lack of holidays. The aspect of constraints (rigor) involves detecting all incoming signals, performing tasks according to strictly defined standards, fixed position during work, doing work in a cramped, skilled work space, limited influence on decision making with whom the job is shared. External time pressure (time limit) implies the impossibility of delaying decisions, reduced ability to control task execution, the need for speeding up the work, and the existence of a time limit for performing some work. Exposure to external noxious agents means exposure to blinding light, flashes, noise, vibrations, temperature extremes, gases, vapors, dust, and lifting loads. Avoidance of danger (an aversion) as an element of mental stress involves constant readiness to avoid possible serious consequences, presence visually disturbing scenes and events, work in the presence of flammable substances, an accident, testifying in court for an accident at work. Conflicts mean that there is an unclear difference between various incoming signals, the lack of essential information for decision making, the obtaining of contradictory information, the confrontation with unexpected events that require the change of the previous work plan, creating conflict and uncertainty in decision making, interruptions in the work of other people, working atmosphere burdened with interpersonal conflicts, lack of support and assistance from colleagues, inability to progress in the profession, work relationship at a certain time or threat of cancellation, violation of one's own norms and rules of conduct. The Professional Stress Index (OSI) is the main sum of the whole model and gives the characteristics and size of stress in the workplace. In relation to the value of OSI, the respondents in this study are divided into two groups. The ex- amined group consisted of 1350 construction workers from several companies who were exposed to stress at work, with an OSI value of over 60, and were mainly workers working at height, handling construction machinery and exposed to increased psychophysical efforts and the effects of physical and chemical harm. The control group consisted of 550 administrative workers from several construction companies who worked at workplaces and in conditions where the OSI was below 60 . The average age of the group was $53.8 \pm 10.5$ years and control group workers $54.7 \pm 11,5$ years, which does not represent a statistically significant difference ( $p>0.05)$. In the examined group, $51.3 \%$ were smokers, and $48.9 \%$ of the workers constantly consumed cigarettes, which is not statistically significant ( $p>0.05$ ). Blood pressure was measured in all workers. Chronic elevations in blood pressure over 140/90 mm Hg were considered as arterial hypertension. In the case of workers with arterial hypertension, a detailed analysis of the health status and assessment of the work ability for the work that was performed at that moment was performed. In addition to work, personal, family and social history was gathered, data on problems including laboratory tests (sedimentation of erythrocytes, blood test results, urine examination, glycemia, cholesterol, triglycerides, electrolytes, urea, creatinine, acidum uricum), EKG, echocardiographic examination, physical exercise test with determination of the consumption of oxygen during the test, ultrasound examination of the kidney. In relation to complications of arterial hypertension, workers are classified into one of five groups:

1. Arterial hypertension without complications - in case that no complications are found on vital organs,

2. Arterial hypertension with heart complications - in case of heart rhythm disturbances, coronary disease, hypertrophy, or myocardial left ventricular dilation,

3. Arterial hypertension with complications in the eye bottom - in case of changes in blood vessels of the retina,

4. Arterial hypertension with complications on the central nervous system,

5. Arterial hypertension with complications on other organs - in the event of complications on other organs (kidney, peripheral blood vessels).

Based on the analysis of working conditions, working environment, health status and estimation of the functional capacity of the cardiovascular system, an opinion was given on the working ability of each respondent. The results are statistically processed and shown in the table.

\section{Results}

By analyzing the demands of jobs, the presence of noxious agents and the analysis of professional stressors in workplaces, it has been noticed that the workers of the investigated group were exposed to a statistically significantly higher level of the index of total professional stress $(85.89 \pm 4.21, \min =60.5, \max =90)$ 
groups $(55.53 \pm 3.92, \min =45.5, \max =59.5)$. Values for all groups except the work stressors, stress from the group of a time limit, a statistically significantly higher in the experimental compared to control group (Table 1).

Arterial hypertension is statistically significantly more frequent among the workers in examined group (40.3\%) compared to control group workers $(24.1 \%)$ (p $<0.05)$. Arterial hypertension without complications on vital organs was statistically significantly more common among examined workers $(30.9 \%)$ compared to control group workers $(19.1 \%)$ ( $\mathrm{p}<0.05)$. Among the complications of this disease in both groups dominated by changes in the heart and the eyelid (Table 2).

By monitoring the prevalence of arterial hypertension in relation to the work experience in the examined group, an increase in prevalence with years of service is recorded as both arterial hypertension without complications and arterial hypertension with complications. The prevalence of arterial hypertension without complications but also with complications on vital organs statistically significantly increases in groups of workers with a working experience over 21 years (Table 3 ).
The analysis of the the results of the assessment of working capacity showed that in the tested group there is significantly higher number of workers sent to the disabled workers' committee because of a total loss of working ability in comparison to the control group. In the control group, there was a statistically significant increase in the number of workers who were able to continue their work in relation to the tested group of workers (Table 4).

By monitoring the results of the evaluation of the work ability in relation to the value of the index of professional stress, it is noticed that with the increase in the OSI level, the number of workers sent to the disabled workers' committee due to complete loss of working ability is increasing. The number of workers with complete loss of working ability is statistically significantly increased in the subgroups of workers who are exposed to OSI over 71, in which statistically significantly higher number of workers with complete loss of working ability are registered in relation to the number of workers able to work (Table 5).

Table 1 Values of professional stressors and the total index of professional stress at the control and examination groups.

\begin{tabular}{lrrrrr}
\hline Professional stressors & \multicolumn{2}{c}{ Examined group } & \multicolumn{2}{c}{ Control group } & p \\
& $\mathrm{X}$ & $\mathrm{SD}$ & $\mathrm{X}$ & $\mathrm{SD}$ & \\
\hline High job requirements & 19.34 & 5.15 & 10.05 & 4.27 & $<0.001$ \\
Strictness & 15.42 & 2.02 & 10.13 & 3.68 & $<0.001$ \\
Conflict & 16.57 & 4.74 & 9.38 & 2.58 & $<0.001$ \\
Underload & 5.98 & 1.64 & 11.71 & 3.98 & $<0.001$ \\
Exposure to noxiousness & 12.21 & 5.75 & 6.23 & 1.58 & $<0.001$ \\
Time limit & 7.13 & 1.81 & 6.72 & 1.75 & n.s. \\
Exposure to noxious agents & 9.24 & 1.48 & 1.31 & 1.10 & $<0.001$ \\
\hline OSI total & 85.89 & 4.21 & 55.53 & 3.92 & $<0.001$ \\
\hline
\end{tabular}

n.s.- difference is not significant

Table 2 Prevalence of arterial hypertension in the examined and control group

\begin{tabular}{|c|c|c|c|c|c|}
\hline & \multicolumn{2}{|c|}{$\begin{array}{c}\text { Examined group } \\
\mathrm{N}=1350\end{array}$} & \multicolumn{2}{|c|}{$\begin{array}{c}\text { Control group } \\
\mathrm{N}=550\end{array}$} & \multirow[t]{2}{*}{$\mathrm{p}$} \\
\hline & Number & $\%$ & Number & $\%$ & \\
\hline Arterial hypertension without complications & 418 & 30.5 & 105 & 19.1 & $0<0.05$ \\
\hline Arterial hypertension with complications on the heart & 55 & 4.1 & 13 & 2.4 & n.s. \\
\hline Arterial hypertension with complications on the eyelet & 50 & 3.7 & 12 & 2.2 & n.s. \\
\hline Arterial hypertension with complications on the central nervous system & 15 & 1.1 & 2 & 0.4 & n.s. \\
\hline Arterial hypertension with complications on other organs & 5 & 0.4 & 1 & 0.2 & n.s. \\
\hline Total & 543 & 40.3 & 133 & 24.1 & $0<0.05$ \\
\hline
\end{tabular}

n.s.- difference is not significant

Table 3 Arterial hypertension in the examined and control group in relation to the work experience.

\begin{tabular}{|c|c|c|c|c|c|c|c|c|c|c|c|c|}
\hline \multirow{3}{*}{$\begin{array}{c}\text { Working } \\
\text { expirience } \\
\text { (years) }\end{array}$} & \multicolumn{5}{|c|}{ Examined group } & \multicolumn{5}{|c|}{ Control group } & \multirow[t]{3}{*}{ p 1} & \multirow[t]{3}{*}{$\mathrm{p} 2$} \\
\hline & \multirow[t]{2}{*}{$\mathrm{N}$} & \multicolumn{2}{|c|}{$\begin{array}{c}\text { Hypertension without } \\
\text { complications }\end{array}$} & \multicolumn{2}{|c|}{$\begin{array}{c}\text { Hypertension } \\
\text { with complications }\end{array}$} & \multirow[t]{2}{*}{$\mathrm{N}$} & \multicolumn{2}{|c|}{$\begin{array}{c}\text { Hypertension without } \\
\text { complications }\end{array}$} & \multicolumn{2}{|c|}{$\begin{array}{c}\text { Hypertension } \\
\text { with complications }\end{array}$} & & \\
\hline & & $\mathrm{n}$ & $\%$ & $\mathrm{n}$ & $\%$ & & $\mathrm{n}$ & $\%$ & $\mathrm{n}$ & $\%$ & & \\
\hline$<10$ & 340 & 57 & 16.7 & 13 & 3.82 & 139 & 25 & 17.9 & 5 & 3.6 & n.s & n.s \\
\hline $11-20$ & 338 & 61 & 18.1 & 17 & 5.03 & 137 & 25 & 18.3 & 8 & 5.8 & n.s & n.s \\
\hline $21-30$ & 345 & 145 & 42.0 & 48 & 13.9 & 140 & 27 & 19.3 & 8 & 5.7 & $<0.05$ & $<0.05$ \\
\hline $31-40$ & 327 & 155 & 47.4 & 47 & 14.4 & 134 & 28 & 20.9 & 7 & 5.2 & $<0.05$ & $<0.05$ \\
\hline Total & 1350 & 418 & 30.9 & 125 & 9.2 & 550 & 105 & 19.1 & 28 & 5.1 & $<0.05$ & $<0.05$ \\
\hline
\end{tabular}

p1 - statistical significance of difference between test and control group in the presence of arterial hypertension without complications p2 - statistical significance of difference between test and control group in the presence of arterial hypertension with complications 
Table 4 Results of assessment of the working ability of workers with arterial hypertension in the examined and control group

\begin{tabular}{|c|c|c|c|c|c|c|c|c|c|c|c|c|}
\hline & \multicolumn{5}{|c|}{ Examined group } & \multicolumn{5}{|c|}{ Control group } & \multirow[t]{3}{*}{$\mathrm{p} 1$} & \multirow[t]{3}{*}{$\mathrm{p} 2$} \\
\hline & \multirow[t]{2}{*}{$\overline{\mathrm{N}}$} & \multicolumn{2}{|c|}{$\begin{array}{c}\text { Capable for } \\
\text { work }\end{array}$} & \multicolumn{2}{|c|}{$\begin{array}{l}\text { Referred to the } \\
\text { Disability } \\
\text { Commission }\end{array}$} & \multirow[t]{2}{*}{$\mathrm{N}$} & \multicolumn{2}{|c|}{$\begin{array}{l}\text { Capable for } \\
\text { work }\end{array}$} & \multicolumn{2}{|c|}{$\begin{array}{c}\text { Referred to the } \\
\text { disabled workers' } \\
\text { committee }\end{array}$} & & \\
\hline & & $\mathrm{n}$ & $\%$ & $\mathrm{n}$ & $\%$ & & $\mathrm{n}$ & $\%$ & $\mathrm{n}$ & $\%$ & & \\
\hline Hypertension without & 418 & 245 & 58.6 & 173 & 41.4 & 105 & 103 & 98.1 & 2 & 1.9 & $<0.05$ & $<0.05$ \\
\hline Hypertension with complications & 125 & 11 & 8.8 & 114 & 91.2 & 28 & 27 & 96.4 & 1 & 3.6 & $<0.05$ & $<0.05$ \\
\hline Total & 543 & 256 & 47.1 & 287 & 52.8 & 133 & 130 & 97.7 & 3 & 2.2 & $<0.05$ & $<0.05$ \\
\hline
\end{tabular}

Table 5 Results of the evaluation of working capacity in relation to the value of OSI

\begin{tabular}{|c|c|c|c|c|c|c|c|}
\hline \multirow[t]{2}{*}{$\overline{\text { OSI }}$} & \multicolumn{3}{|c|}{ Capable for work } & \multicolumn{3}{|c|}{$\begin{array}{l}\text { Referred to the } \\
\text { Disability Commission }\end{array}$} & \multirow[t]{2}{*}{$\mathrm{p}$} \\
\hline & $\mathrm{N}$ & number & $\%$ & $\mathrm{~N}$ & number & $\%$ & \\
\hline $60-70$ & 481 & 203 & 42.2 & 181 & 78 & 43.1 & n.s. \\
\hline $71-80$ & 453 & 39 & 8.6 & 186 & 91 & 48.9 & $<0.05$ \\
\hline $81-90$ & 416 & 14 & 3.4 & 183 & 118 & 64.5 & $<0.05$ \\
\hline
\end{tabular}

\section{Discussion}

In this study it was determined that construction workers are exposed to high levels of occupational stress. Similar results have been found by other authors who have studied the working conditions of construction workers [11]. At workplaces construction workers registered with stress factors that could affect the occurrence, evolution and flow of arterial hypertension, which should be taken into account when making the final opinion of the working ability of these workers [12]. In this study, high prevalence of arterial hypertension among construction workers $(40.3 \%)$ was established. The prevalence of arterial hypertension registered in this study is higher than in the results reported by other authors who have followed the risk factors for cardiovascular disease in construction workers in other environments. Thus, Prabhakaran [13] states that $32 \%$ of construction workers have arterial hypertension, and Sze Pui Pamela Tin states in his research the prevalence of arterial hypertension among construction workers in $22.6 \%$ [14]. These differences in prevalence can be explained by differences in age among the surveyed population groups of construction workers (in the Sze Pui Pamela Tin survey, the average age of construction workers was $43.1 \pm 11.5$ years, and in this survey the average age of construction workers is $53.8 \pm$ 10.5 years) and different lifestyles and habits $(51.3 \%$ of smokers among construction workers in this study while there were $39.1 \%$ smokers in Sze Pui Pamela Tin's research). There is convincing evidence in the literature that the factors of occupational exposure (stressed professional noxious agents and job requirements) can be favorable factors in the faster development of arterial hypertension [15-17]. Peters found that high-demand jobs and small controls over them, such as building workers, lead to a rise in blood levels of catecholamines and cortisols, which among other things results in an increase in blood pressure [18]. According to the literature, a significant correlation between the high demands of work, arterial hypertension and cardiovascular disease $[19,20]$ was established. The restriction (strictness) of construction workers is reflected in the need to carry out jobs according to strictly defined standards and according to the results of previous research it may be a risk factor for the cardiovascular system [21,22]. The external time pressure that as a professional stressor in construction workers means that the worker has no influence on the pace of work and decision-making that cannot be postponed or indirectly involves long hours. Long working hours in epidemiological studies have been proven to be a stressful workplace and a factor contributing to the faster development of arterial hypertension and coronary disease [23-26]. Conflicts in the workplace, present in the subjects in this paper, arise when the work or work rhythm breaks up, leading to the occurrence of professional stress. There is an increase in arterial blood pressure and less satisfaction with work [27-28]. Unpredictable changes in the plan lead to the creation of new plans, which requires additional effort and stress [29]. One of the stressed noxious agents in the working environment of the construction workers is industrial noise. Clinical studies have shown that industrial noise is a significant factor contributing to the faster arterial hypertension in exposed workers [30-32], where the noise present in the community environment highlights the harmful effects of industrial noise on the blood pressure of exposed workers [33]. Noise can cause an increase in blood pressure and the occurrence of arterial hypertension by various mechanisms. Possible pathogenetic mechanisms are the influence of noise on the increase in circulating catecholamine concentrations released from the adrenal medulla as a result of activation of the adrenergic nervous system, the effect of higher adrenal steroid concentrations, the increased activity of the renin-angiotensin-al- 
dosterone system under the effect of noise, and the effect of noise on the increase in total peripheral vascular resistance [34]. Neuroanatomic relationships in the central nervous system allow acoustic stimulus not only to affect the auditory area of the bark of the large brain, but also the limbic system, that is, the hypothalamus, leading to stimulation of the sympathetic and vasoconstriction on the periphery, resulting in an increase in peripheral resistance and an increase in blood pressure. Constantly repeated noise stimulation, in time, leads to chronic elevation of sympathetic tone, which can accelerate various structural changes on the vascular system and increase the peripheral resistance of the blood vessels leading to permanent arterial hypertension [35]. Over time, arterioles hypertrophy, thickness of the blood vessel wall increases and blood vessel sensitivity increases. Professional exposure to vibrations, the same pathogenetic mechanisms as noise, can favor a more frequent occurrence of arterial hypertension and coronary disease [36]. Working in the presence of inadequate air temperature of the working environment is a stress for the body of the worker, which in time leads to an increase in blood pressure and arterial hypertension [37-39]. This reaction of the cardiovascular system depends on the age of the worker, the level of workload and the genetic predisposition of the worker [40,41]. There is increasing evidence that long-term work in conditions of reduced outdoor air temperature can potentiate the development and occurrence of arterial hypertension in exposed workers [42,43]. A monotonous work involving repeatedly recurring activities is associated with a more frequent occurrence of arterial hypertension, coronary disease, diabetes mellitus, and hypercholesterolemia of exposed workers [44], which can be partly explained by a greater number of smokers among workers who perform monotonous activities $[45,46]$. Working in shifts and during the night, the happiness of the construction workers leads to the disruption of circadian rhythm and can be a significant favoring factor in the faster arterial hypertension $[47,48]$. Workers who work in shifts due to circadian rhythm disorders often suffer from arterial hypertension [49,50], which can be explained by the frequent occurrence of the habit of consuming cigarettes, alcohol and caloric food among "shift workers", and a more frequent occurrence of neuroses among workers working in shifts [51,52]. There is more and more convincing evidence that a chronic exposure to chemical agents at the workplace contributes to the faster arterial hypertension of exposed workers [53,54]. Some authors found a greater prevalence of ischemic heart disease, arterial hypertension, and kidney disease in residents living near lead smelters [55]. Simultaneous exposure to noise, lead, manganese and inadequate microclimate factors contributes to the more frequent occurrence of arterial hypertension of exposed workers [56]. Organic solvents lead to an increased release of catecholamines from the adrenal gland and to an acid-base disorder, which can negatively affect blood pressure regulation and circulation [57]. In a group of organic solvents, carbon dioxide takes a special place that leads to lipid metabolism disorders, favors the atherosclerosis process, suppresses the thyroid gland (can lead to hypothyroidism) and potentiates the development of arterial hypertension faster $[58,59]$. Constant exposure to vinyl chloride leads to an increase in the secretion of catecholamine and peripheral circulation disorders [60-62]. This study analyzed separately working ability of patients with arterial hypertension and its complications. The most important factors determining the working ability of workers with arterial hypertension are the biological demands of the workplace (in particular the level and type of workload, the presence of stressed nose and those harmful effects that affect the height of blood pressure and the occurrence of complications of arterial hypertension), the functional state of the cardiovascular system, arterial hypertension, age, year of work experience and employee motivation. Assessment of the working ability of patients with arterial hypertension and complications is done by aligning the biological functions of the organism with the requirements, risks and characteristics of the workplace. In assessing work ability, the psycho-physical and psychophysiological potentials first must be defined. Diagnostic procedures assess the health characteristics of the organism, the functional working capacity and the functional state of organs and organic systems. At the same time, an analysis of biological demands, loads and occupational risks in the workplace is carried out. In the end, the data obtained from previous actions are harmonized [63]. Opinion on working abilities is mostly based on the exercise of physical effort in the conditions of professional harmfulness. The results of this paper indicate high correlation between the presence of professional stressors and the complete loss of working ability. The correlation of permanent total loss of working ability and professional stressors can be explained by their impact on increased job dissatisfaction [64,65] and more frequent presence of risk factors for coronary disease in exposed subjects that lead to complications of arterial hypertension of the heart [66-68], stress caused by vascular complications in the central nervous system $[69,70]$, cardiomyopathy [71], and atherosclerotic changes due to the action of professional stressors [72-74].

\section{Conclusion}

Professional stress is an important factor that affects the frequent occurrence of arterial hypertension and its complications in exposed workers. The prevalence of arterial hypertension and its complications increases with the duration of exposure to professional stress and in particular statistically significantly increases in workers with working experience over 21 years. Stress at work is a factor that significantly affects the total loss of working ability of exposed workers. The values of the index of professional stress over 71 significantly affect the complete loss of the permanent working capacity of the exposed workers in construction. 


\section{References}

1. Siegrist J, Sies H. Disturbed Redox Homeostasis in Oxidative Distress: A Molecular Link From Chronic Psychosocial Work Stress to Coronary Heart Disease? Circ Res. 2017; 121(2):103-105.

2. Ushakov AV, Ivanchenko VS, Gagarina AA. Psychological Stress in Pathogenesis of Essential Hypertension. Curr Hypertens Rev 2016; 12(3):203-214.

3. Djindjić N, Jovanović J, Djindjić B, Jovanović M, Pesić M, Jovanović JJ. Work stress related lipid disorders and arterial hypertension in professional drivers - a cross-sectional study. Vojnosanit Pregl 2013; 70(6):561-568.

4. Manohar S, Thongprayoon C, Cheungpasitporn W, Mao MA, Herrmann SM. Associations of rotational shift work and night shift status with hypertension: a systematic review and metaanalysis.J Hypertens 2017; 35(10):1929-1937.

5. Rapsomaniki E, Timmis A, George J, Pujades-Rodriguez M, Shah AD, Denaxas S, et al. Blood pressure and incidence of twelve cardiovascular diseases: lifetime risks, healthy life-years lost, and age-specific associations in $1 \cdot 25$ million people. Lancet 2014; 383: 1899-1911.

6. Bauer UE, Briss PA, Goodman RA, et al. Prevention of chronic disease in the 21st century: elimination of the leading preventable causes of premature death and disability in the USA. Lancet $2014 ; 384: 45-52$.

7. Jovanović J, Jovanović M, Batanjac J. Arterial hypertension at industrial workers, Vojnosanit Pregl 1999; 56(3):275-282.

8. Jong-Uk W, Inah $\mathrm{K}$. Compensation for Work-Related Cerebrocardiovascular Diseases. J Korean Med Sci 2014; 29 (Suppl):S12-S17.

9. Lazaridis K, Jovanović J, Jovanović JJ, Šarac I, Jovanović S. The impact of occupational stress factors on temporary work disability related to arterial hypertension and its complications. Int J Occup Saf Ergon 2017; 23(2):259-266.

10. Belkić K. The Occupational Stress Index: An Approach Derived from Cognitive Ergonomics and Brain Research for Clinical Practice, Cambridge International Science Publishing, Cambridge, 2003, ISBN: 1-898326-02-9.

11. Poon S, Rowlinson S, Koh T, Deng Y. Job Burnout and Safety Performance in the Hong Kong Construction Industry. International Journal of Construction Management 2013; 13(1):69-78.

12. Jovanović J, Jovanović M, Đorđević D. Estimation of working ability at workers with arterial hypertension, Vojnosanit Pregl 2001; 58(6):631-639.

13. Prabhakaran D Shah P, Chaturvedi V, Ramakrishnan L, Manhapra A, Reddy KS. Cardiovascular risk factor prevalence among men in a large industry of northern India.Natl Med J India 2005; 18(2):59-65.

14. Sze PT, Wendy WTL, Sungwon Y, Zhang N, Nan X, Weiwei Z, $\mathrm{Ke} \mathrm{M}$ et al. Workplace Health Promotion: Assessing the Cardiopulmonary Risks of the Construction Workforce in Hong Kong. PLoS One 2016; 11(1):e0146286. doi: 10.1371/journal. pone.0146286, PMCID: PMC4723250

15. Jayakumar D. Occupational Stress and Hypertension among Railway Loco Pilots and Section Controllers.Indian J Occup Environ Med 2017; 21(1):23-28.

16. Jovanović J, Jovanović M. Occupational stress and arterial hypertension. Med Pregl 2004; 57(3-4):153-158.

17. Liu MY, Li N, Li WA, Khan H. Association between psychosocial stress and hypertension: a systematic review and meta-analysis. Neurol Res 2017; 39(6):573-580.

18. Peters ML, Godaert GL, Ballieux RE, van Vliet M, Williemsen JJ, Sweep FC. Cardiovascular and endocrine response to experimental stress: effects of mental effort and controllability. Psichoneuroendocrinology 1998; 23:1-17.

19. Gilbert-Ouimet M, Trudel X, Brisson C, Milot A, Vézina M. Adverse effects of psychosocial work factors on blood pressure: systematic review of studies on demand-control-support and effort-reward imbalance models. Scand J Work Environ Health 2014; 40(2):109-132.

20. Nieuwenhuijsen K, Bruinvels D, Frings-Dresen M. Psychosocial work environment and stress-related disorders, a systematic review. Occup Med (Lond) 2010; 60(4):277-286.
21. Netterstrom B, Nielsen FE, Kristensen TS, Bach E, Moller L. Relation between job strain and myocardial infarction: a case control study. Occup Environ Med 1999; 56(5):339-342.

22. Djindjic N, Jovanovic J, Djindjic B, Jovanovic M, Jovanovic JJ. Associations between the occupational stress index and hypertension, type 2 diabetes mellitus, and lipid disorders in middle-aged men and women. Ann Occup Hyg 2012; 56(9): 10511562.

23. Spurgeon A, Harrington JM, Cooper CL. Health and safety problems associated with long working hours. A review of the current position. Occup Environ Med 1997; 54:367-375.

24. Hino A, Inoue A, Kawakami N, Tsuno K, Tomioka K, Nakanishi M, Mafune K, Hiro H. Buffering effects of job resources on the association of overtime work hours with psychological distress in Japanese white-collar workers.Int Arch Occup Environ Health 2015; 88(5):631-640.

25. Yang H, Schnall PL, Jauregui M, Su TC, Baker D. Work hours and self-reported hypertension among working people in California. Hypertension 2006; 48(4):744-750.

26. Kivimäki M, Solja T. Nyberg, G. David Batty, Kawachi I, Markus J, Lars A et al. Long working hours as a risk factor for atrial fibrillation: a multi-cohort study. Eur Heart J 2017; 38(34):26212628.

27. Kahn RL. Conflict, ambiguity and overload: three elements in job stress. In: McLean A. Ocupational Stress. Springfield: Charles C Thomas, 1974: 47-61.

28. Panter-Brick C, Eggerman M, Mojadidi A, McDade TW. Social stressors, mental health, and physiological stress in an urban elite of young Afghans in Kabul. Am J Hum Biol 2008; 20(6):627-641.

29. Karlsbeek JWH. Standards of acceptable load in ATC tasks. Ergonomics 1971; 14:641-650.

30. Verbeek JH, Dijk FJ, Vries FF. Non auditory effects of noise in industry. Int Arch Occup Environ Health 1987; 59(1):51-54.

31. Jovanović J, Batanjc J, Jovanović M. Circulatory effects of industrial noise and vibrations. Annals of the Institute of Public Health, Timisoara, Romania, XXII 1997; 5 (14): 99-101.

32. Münzel T, Schmidt FP, Steven S, Herzog J, Daiber A, Sørensen M. Environmental Noise and the Cardiovascular System. J Am Coll Cardiol 2018; 71(6):688-697.

33. Jovanović J, Popović V, Milošević Z, Jovanović M. Cumulative effects of communal and industrial noise on cardiovascular system. Facta Universitatis Series Medicine and Biology 1997; 4(1):57-61.

34. Paunović K, Jakovljević B, Stojanov V. The timeline of blood pressure changes and hemodynamic responses during an experimental noise exposure. Environ Res 2018; 163:249-262.

35. Vacheron A. Cardiovascular effects of noise. Bull Acad Natl Med 1992; 176(3):387-392. [In French]

36. Tzvetkov D, Boev M, Baykoushev B. Vibrations-discriminant models and possibilities for prognosticating specific and non specific effects on the organism. Ann Occup Hyg 1992; 36(3): 253-264.

37. Xu LJ, Li DG, Holbrrook NJ, Udelsman R.. Acute hypertension induces heat shock protein 70 gene expression in rat aorta. Circulation 1995; 92(5):1223-1229.

38. Brook RD. The Environment and Blood Pressure. Cardiol Clin 2017; 35(2):213-221.

39. Valutsina VM, Tkachenk, LN. Age related functional characteristics of miners exposed to heat microclime. Med $\mathrm{Tr}$ Prom Ekol 1994; 1,8: 10-15. [In Russian]

40. Blake, MJ, Klevay LM, Halas ES, BodeAM. Blood pressure and heat shock protein expression in response to acute and chronic stress. Hypertension 1995; 25(4):539-544.

41. Havenith G, Inoue Y, Luttikholt V, Kenney NJL. Age predicts cardiovascular, but not thermoregulatory, responses to humid heat stress. Eur J Appl Physiol 1995; 70(1):88-96.

42. Li X, Tokura H, Midorikanja T. The effects of two types of clothing on seasonal cold tolerance. Eur JAppl Physiol 1994; 69(6):498-501.

43. Inoue $\mathrm{Y}$, Nakao M, Ueda $\mathrm{H}$, Araki T. Seasonal variation in physiological responses to mild cold air in young and older men. Int J Biometeorol 1995; 38(3):131-136. 
44. Scansetti G. Arterial hypertension and work activities. Med Lav 1991; 82(3):233-237. [In Italian]

45. Melamed S, Ben Avi I, Lua J, Green MS. Repetitive work ,work underload and coronary heart disease risk factors among blue collar workers, The CORDIS Study. J Psyshosom Res 1995; 39(1):19-29.

46. Neuberger M. Smoking and prevention at the work site. Wien Med Wochenschr 1995; 145(4):90-94..

47. Ohlander J, Keskin MC, Stork J, Radon K. Shift work and hypertension: Prevalence and analysis of disease pathways in a German car manufacturing company. Am J Ind Med 2015; 58(5): 549-560.

48. Hirose T, Ohtake Y, Machida M. The effect of fixed night work on blood pressure of male bakery workers in a processing. Sangyo Eiseigaki Zasshi 1995; 37(1):43-46. [Article in Japanese]

49. Frese M, Semmer N. Shift work, stress and psychosomatic complaints: a comparison between workers in different shift work schedules, non shift workers and former shift workers. Ergonomics 1986; 29:98-114.

50. Akerstedt T, Knutsson A, Alfredson L, Theorell T. Shift work and cardiovascular disease. Scand J Work Environ Healt 1984; 10: 409-414.

51. Knutsson A. Do shift workers face higher risk of coronary artery disease. In: Oginski A, Pokorski J, Rutenfranz J. Contemporary Advances in Shift Work Research. Krakow, Medical Academy 1987; 305-512.

52. Cervinka R, Kundi M, Koller M, Heider M, Arnof J. Shift related nutrition problems. In: Wedderburn A, Smith P. Psychological approaches to night and Shift work. Edinburgh, Herriot Watt University, 1984; 14:1-18.

53. Yang WY, Efremov L, Mujaj B, Zhang ZY, Wei FF, Huang QF, Thijs L, Vanssche T, Nawrot TS, Staessen JA. Association of office and ambulatory blood pressure with blood lead in workers prior to occupational exposure. J Am Soc Hypertens 2018; 12:14-24.

54. Solomenchuk, TM. The effect of lead compounds on the development of hypertension in workers in the radioelectronics industry. Vrach Delo 1995; 1-2:94-97.

55. Weddeen PR, Mallik KD, Batuman V. Detection and treatment of occupational lead nepropathy. Arch Intern Med 1979; 139:53-61.

56. Kuneva, T. The incidence of paraprofessional diseases in employees of the Research Institute of Ferros Metallurgy in Kremikovtsi. Probl Khig 1992; 17:218-227.

57. Mohammadi S, Golabadi M, Labbafinejad Y, Pishgahhadian F, Attarchi M. Effects of exposure to mixed organic solvents on blood pressure in non-smoking women working in a pharmaceutical company. Arh Hig Rada Toksikol 2012; 63(2):161-169.

58. Chrostek MJ, Czeczotko B. The evaluation of the health state of the workers occupationally exposed to low concentration of carbon disulphide (CS2). Part one: General medical examination and laboratory tests. Przegl Lek 1995; 52(5):249-251.

59. Stanosz S, Kuligonjski D, Pieleszek A, Zuk E, Rzechula D, Chlubek D. Concentration of dopamine in plasma, activity of dopamine beta-hydroxylase in serum and urinary excretion of free catecholamines and vanillylmandelic acid in women chronically exposed to carbon disulphide. Int $\mathrm{J}$ Occup Med Environ Health 1994; 7(3):257-261.

60. Misgeld V, Stolpmann HJ, Schultes S. Intoxication by vinil chloride polymers and /or their additives. Z Haut Geschlechtskrank 1973; 48:425-431.

61. Tania C, Misty JH, Kevin WH, Susan MV, Avima MR. Coronary Artery Disease and Cancer Mortality in a Cohort of Workers Exposed to Vinyl Chloride, Carbon Disulfide, Rotating Shift Work, and o-Toluidine at a Chemical Manufacturing Plant. Am J Ind Med 2014; 57(4):398-411.

62. Mariclj HR, Darke CS, Archibald R, Leroy EC. In vivo observations of skin capillaries in workers exposed to vinyl chloride, An English-American Comparison. Brit J Ind Med 1978; 35:1-12.

63. Anbazhagan S, Ramesh N, Surekha A, Fathima FN, Melina A. Estimation of work capacity and work ability among plantation workers in South India. Indian J Occup Environ Med 2016; 20(2):79-83.

64. de Croon EM, Blonk RW, de Zwart BC, Frings-Dresen MH, Broersen JP. Job stress, fatigue, and job dissatisfaction in Dutch lorry drivers: towards an occupation specific model of job demands and control. Occup Environ Med 2002; 59(6):355-362.

65. Delp L, Wallace SP, Geiger-Brown J, Muntaner C. Job stress and job satisfaction: home care workers in a consumer-directed model of care. Health Serv Res 2010; 45(4):922-940.

66. Chandola T, Brunner E, Michael M. Chronic stress at work and the metabolic syndrome: prospective study. BMJ 2006; 332(7540): 521-525.

67. Momen A, Mascarenhas V, Gahremanpour A, Zhaohui G, Moradkhan R, Kunselman A, Boehmer JP, Sinoway LI. Leuenberger UA. Coronary blood flow responses to physiological stress in humans. Am J Physiol Heart Circ Physiol 2009; 296(3): H854-H861.

68. Kubzansky LD, Thurston RC. Emotional vitality and incident coronary heart disease: benefits of healthy psychological functioning. Arch Gen Psychiatry 2007; 64(12):1393-1401.

69. Surtees PG, Wainwright NW, Luben RN, Wareham NJ, Bingham SA, Khaw KT. Psychological distress, major depressive disorder, and risk of stroke. Neurology 2008; 70:788-794.

70. Kotlęga D, Gołąb-Janowska M, Masztalewicz M, Ciećwież S, Nowacki P. The emotional stress and risk of ischemic stroke. Neurol Neurochir Pol 2016; 50(4):265-270.

71. Costa G. Cardiopathy and stress-inducing factors. Med Lav 2004; 95(2):133-139.

72. Chumaeva N, Hintsanen M, Ravaja N, Juonala M, Raitakari OT, Keltikangas-Järvinen L. Chronic stress and the development of early atherosclerosis: moderating effect of endothelial dysfunction and impaired arterial elasticity. Int J Environ Res Public Health 2009; 6(12):2934-2949.

73. Greenlund KJ, Kiefe CI, Giles WH, Liu K. Associations of job strain and occupation with subclinical atherosclerosis: The CARDIA Study. Ann Epidemiol 2010; 20(5):323-331.

74. Kiarri NK, Abbi D, Mercedes RC, Hilary AT, Kiang L. Chronic Stress and Endothelial Dysfunction: The Multi-Ethnic Study of Atherosclerosis (MESA). Am J Hypertens 2017; 30(1):75-80. 